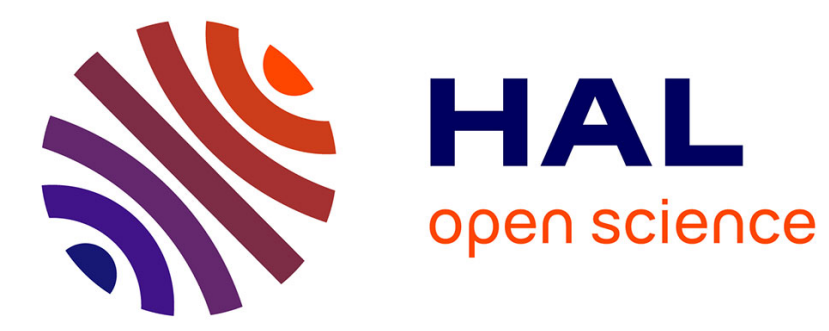

\title{
Herpes simplex virus resistance to antivirals
}

Sonia Burrel, Dimitrios Topalis, David Boutolleau

\section{To cite this version:}

Sonia Burrel, Dimitrios Topalis, David Boutolleau. Herpes simplex virus resistance to antivirals. Virologie, 2020, 24 (5), pp.325-342. 10.1684/vir.2020.0864 . hal-03162633

\section{HAL Id: hal-03162633 \\ https://hal.sorbonne-universite.fr/hal-03162633}

Submitted on 8 Mar 2021

HAL is a multi-disciplinary open access archive for the deposit and dissemination of scientific research documents, whether they are published or not. The documents may come from teaching and research institutions in France or abroad, or from public or private research centers.
L'archive ouverte pluridisciplinaire HAL, est destinée au dépôt et à la diffusion de documents scientifiques de niveau recherche, publiés ou non, émanant des établissements d'enseignement et de recherche français ou étrangers, des laboratoires publics ou privés. 


\section{Résistance des virus herpes simplex aux antiviraux}

\section{Herpes simplex virus resistance to antivirals}

Sonia Burrel ${ }^{1,2}$, Dimitrios Topalis ${ }^{3}$, David Boutolleau ${ }^{1,2}$

1. Centre national de référence (CNR) Herpèsvirus (laboratoire associé), Service de Virologie, Hôpital Pitié - Salpêtrière, AP-HP. Sorbonne Université, Paris, France

2. Sorbonne Université, INSERM U1136, Institut Pierre Louis d'Epidémiologie et de Santé Publique (iPLESP), Paris, France

3. Laboratory of Virology and Chemotherapy, Rega Institute for Medical Research and University of Leuven - KU Leuven, Leuven, Belgium

Correspondance à adresser à :

Dr Sonia Burrel

Service de Virologie

Hôpital Pitié - Salpêtrière

83 boulevard de l'hôpital

75652 Paris cedex 13

Tel : 0142177402

Fax : 0142177411

Courriel : sonia.burrel@aphp.fr 
Résumé. Les infections par les virus herpes simplex (HSV) constituent une cause majeure de morbidité chez les patients immunodéprimés tels que les receveurs de greffe ou les individus infectés par le virus de l'immunodéficience humaine (HIV). Les molécules antivirales utilisées pour le traitement de ces infections sont actuellement peu nombreuses : (val)aciclovir, foscarnet et cidofovir. L'instauration de traitements antiviraux préventifs ou curatifs, souvent durant des périodes prolongées, chez des patients dont l'immunité cellulaire est altérée, peut conduire à l'émergence de résistance des HSV aux antiviraux, compliquant alors la prise en charge thérapeutique de l'infection virale. La persistance de lésions herpétiques après 10 jours de traitement antiviral bien conduit doit faire suspecter une résistance virologique. II est possible de détecter cette résistance par des méthodes génotypiques (identification de mutations associées à la résistance aux antiviraux par séquençage des gènes codant les protéines virales directement impliquées dans le mécanisme d'action des antiviraux) ou par des méthodes phénotypiques (mesure de la concentration d'un antiviral inhibant $50 \%$ de la multiplication virale en culture de cellules). La prévalence de la résistance des HSV à l'aciclovir est inférieure à $1 \%$ chez les individus immunocompétents, hormis ceux souffrant de kératite herpétique pour qui elle est de l'ordre de $7 \%$, et elle varie de $2,5 \%$ à $11 \%$ chez les individus immunodéprimés. De plus, il existe d'autres limitations à l'utilisation de ces antiviraux, comme leurs effets indésirables ou l'impossibilité d'éradiquer les infections virales latentes. A ce jour, de nouveaux composés en cours d'essais cliniques et de nouvelles cibles virales potentielles semblent très prometteuses pour agrandir le panel de molécules efficaces pour traiter les infections dues aux HSV.

Mots clés : infection par les HSV ; patients immunodéprimés ; prise en charge thérapeutique ; antiviraux ; résistance aux antiviraux ; nouvelles molécules en développement 
Abstract. Herpes simplex virus (HSV) infections remain an important cause of morbidity among immunocompromised patients, such as transplant recipients and human immunodeficiency virus [HIV]-infected individuals. Only few antiviral drugs are available to treat HSV infections: (val)acyclovir, foscarnet, and cidofovir. Prophylactic and curative antiviral treatments administered during prolonged periods among patients with altered T-cell immunity may lead to the emergence of HSV resistance to antivirals, contributing to a challenging therapeutic management of viral infection. The persistence of herpetic lesions after 10 days of well-conducted antiviral therapy is suggestive of viral resistance. Resistance to antivirals can be detected using genotypic methods (identifications of antiviral resistance-associated mutations by sequencing genes encoding viral proteins involved in the mechanism of action of antivirals) or phenotypic methods (measure of antiviral drug concentration inhibiting $50 \%$ of viral replication in cell culture). The prevalence of HSV resistance to acyclovir is below $1 \%$ in immunocompetent individuals, except those with herpetic keratitis for whom prevalence can reach $7 \%$, and varies from $3.5 \%$ to $11 \%$ in immunocompromised patients. Adverse effects and the absence of eradication of viral latent infection constitute other limits to the use of antiviral drugs. New antiviral compounds undergoing clinical trials and novel potential viral targets seem very promising to enlarge the panel of efficient compound to treat HSV infections.

Key words: HSV infection; immunocompromised patients; therapeutic management; antiviral drugs; resistance to antivirals; development of new compounds 


\section{Introduction}

Les infections par les virus herpes simplex 1 et 2 (HSV-1 et HSV-2) peuvent être à l'origine de manifestations cliniques qui peuvent varier considérablement en fonction de l'âge, du statut immunitaire, et selon que I'on a affaire à une primo-infection ou à une réactivation. Chez les individus immunocompétents, ces infections sont généralement peu symptomatiques et bien contrôlées, à l'exception toutefois de certaines manifestations cliniques qui peuvent montrer un degré de sévérité plus important, comme la kératite herpétique ou l'encéphalite herpétique. Chez les individus immunodéprimés, notamment ceux dont l'immunité cellulaire T est déficiente (patients greffés, infectés par le virus de l'immunodéficience humaine [HIV], traités par chimiothérapie anticancéreuse ou immunothérapie pour une maladie auto-immune, nouveau-nés ...), les infections par les HSV peuvent se manifester par des formes cliniques plus sévères, des lésions extensives et/ou persistantes. Il est donc important de pouvoir disposer de molécules antivirales pour lutter contre ces différentes formes d'infection. Actuellement, l'arsenal thérapeutique pour le traitement des infections par les HSV est limité avec une seule classe de molécules : les inhibiteurs de l'ADN polymérase virale. L'aciclovir, molécule antivirale spécifique, efficace et quasiment atoxique, dont la découverte par Gertrude Elion et John Hitchings a été récompensée par le Prix Nobel de Médecine en 1988, reste encore à ce jour le représentant emblématique des antiherpétiques. Malheureusement, la problématique de l'émergence de résistance virologique à l'aciclovir et le peu d'alternatives thérapeutiques disponibles peuvent complexifier la prise en charge de certains patients. De nouveaux antiviraux sont donc indispensables pour lutter efficacement contre les infections par les HSV : la découverte récente des inhibiteurs du complexe viral hélicase-primase, efficaces et peu toxiques, semble prometteuse.

\section{Mécanisme d'action des antiviraux}

\section{Antiviraux actuellement disponibles}

Les antiviraux anti-HSV regroupent différentes classes de molécules : des analogues de nucléosides (aciclovir [ACV] et penciclovir [PCV]), un analogue de nucléoside phosphonate, ou nucléotide (cidofovir [CDV]) et un analogue de pyrophosphate (foscarnet [FOS]) (Tableau 1 et Figure 1) [1]. Les analogues de nucléosides, ACV et PCV, sont des analogues de la désoxyguanosine dont le sucre (désoxyribose) a été remplacé par une structure acyclique. Ils entrent en compétition avec le nucléoside naturel au niveau de l'ADN polymérase virale pour être incorporés dans l'ADN viral en cours de synthèse. Toutefois, leur incorporation ne permet pas la formation de la liaison phosphodiester avec le nucléotide suivant au cours de l'élongation: ils agissent comme des 
"terminateurs de chaîne ». Le CDV, quant à lui, est un analogue de la désoxycytidine monophosphate. Parmi les molécules disponibles en France pour le traitement des infections par les HSV, I'ACV et sa prodrogue orale le valaciclovir (VACV) sont les molécules de première intention. II est également possible d'utiliser le famciclovir (FCV) prodrogue orale du PCV (Figure 1A). En deuxième intention, le foscarnet (FOS), analogue du pyrophosphate, est classiquement utilisé pour traiter les infections herpétiques dues à une souche de HSV résistante à l'ACV (Figure 1C). Le ganciclovir (GCV), autre analogue de la désoxyguanosine, est actif sur les HSV mais il n'est pas utilisé en pratique clinique, hormis dans certaines situations particulières. Cette molécule, utilisée classiquement pour le traitement des infections par le cytomégalovirus humain (CMV), possède des propriétés neutropéniantes. Ainsi, le GCV est utilisé pour le traitement des co-infections par HSV et CMV ou des infections oculaires par HSV où il peut être utilisé sous forme topique [1]. Le CDV et sa prodrogue le brincidofovir (BCV), également actifs sur les HSV, sont inscrites sur la liste des spécialités disponibles en autorisation temporaire d'utilisation (ATU) (Figure 1B). D'autres molécules anti-HSV, non disponibles en France, sont commercialisées dans d'autres pays comme la brivudine (bromovinyldésoxyuridine, BVdU) et le PCV (Figure 1) [2].

L'intérêt des prodrogues (VACV, FCV et BCV) obtenues par estérification des molécules mères, est de pouvoir être administrées par voie orale du fait de l'amélioration de leur biodisponibilité. L'ACV possède une biodisponibilité faible (15\% à $30 \%)$ alors que celle du VACV, L-valyl ester de l'ACV, est d'environ 55\%. Le FCV correpond à la forme diacétyl ester du 6-désoxy-PCV et permet d'avoir une biodisponibilité d'environ $70 \%$. Il est à noter que le PCV, composé actif en intracellulaire, est 100 fois moins actif que l'ACV sur les HSV, mais cela est compensé par de fortes concentrations cellulaires et une demi-vie longue (7h-20h). Le FOS et le CDV sont, quant à elles, des molécules utilisables uniquement par voie intraveineuse. L'activité antivirale importante du CDV est soutenue par une longue demi-vie intracellulaire des métabolites actifs [3].

Tous ces antiviraux disponibles en pratique clinique ciblent l'ADN polymérase virale et perturbent la réplication du génome viral au cours du cycle de multiplication. La spécificité d'action des analogues de nucléosides ( $\mathrm{ACV}, \mathrm{PCV}, \mathrm{BVdU})$ est fondée sur la première étape de leur activation, à savoir une phosphorylation, qui est assurée par la thymidine kinase (TK) virale, codée par le gène UL23 (Figure 1D ; forme tridimensionnelle de la TK du HSV-1), une enzyme exprimée pendant la phase précoce du cycle de multiplication virale [4]. Outre cette étape d'activation, ces molécules nécessitent plusieurs autres modifications métaboliques successives assurées par des enzymes cellulaires (Tableau 1) [2-5]. Le CDV, analogue de nucléotide, constitue la seule exception parmi les analogues de substrats naturels puisqu'il ne nécessite pas d'activation par la TK virale : il est uniquement phosphorylé par 
des kinases cellulaires. Le FOS, quant à lui, est un inhibiteur direct de l'ADN polymérase virale, codée par le gène UL30 (Figure 1D ; forme tridimensionnelle de l'ADN polymérase du HSV-1).

Les formes actives des analogues de nucléosides, c'est-à-dire leurs formes triphosphates (ex : ACVTP, forme triphosphate de l'ACV), possèdent dans l'ensemble une meilleure affinité pour l'ADN polymérase virale que pour les $\operatorname{ADN}$ polymérases cellulaires $[2,6]$. Outre le fait que ces composés antiherpétiques sont activés de manière spécifique dans les cellules infectées par les HSV, ils sont de plus incorporés de manière préférentielle dans I'ADN viral, ce qui tend à limiter leur toxicité au niveau cellulaire [7]. Le FOS et le CDV sont, quant à eux, néphrotoxiques. La néphrotoxicité du CDV est due au fait qu'il constitue un substrat de l'enzyme cellulaire hOAT1 (human organic anion transporter 1) localisée dans les cellules tubulaires rénales proximales. II est à noter que le BCV, prodrogue du CDV, n'est pas reconnu par cette enzyme et est donc dénué d'effets indésirables au niveau rénal. [8-10].

\section{TK virale : enzyme clé de l'activation des analogues nucléosidiques}

La TK virale est codée par le gène UL23 (1131 paires de bases [pb]) dans le génome des HSV. II s'agit d'une protéine de 376 acides aminés (environ 42 kilo Daltons [kDa]). II existe au moins 80\% d'homologie nucléotidique entre la TK du HSV-1 et celle du HSV-2, et l'identité en acides aminés atteint environ $70 \%$. Cette enzyme est composée de deux domaines de liaison, un pour le donneur de phosphate à partir d'adénosine triphosphate (ATP) et un pour l'accepteur de phosphate (le nucléoside). Elle possède en outre une structure tridimensionnelle commune aux nucléosides kinases cellulaires, à savoir de 7 feuillets $\beta$ et de 15 hélices $\alpha$, et possède une zone centrale dite "core » protéique. Majoritairement sous forme de monomère, la TK peut aussi se présenter sous forme de dimère. Le domaine de dimérisation au niveau de la structure tridimensionnelle regroupe les résidus de plusieurs hélices $\alpha(\mathrm{H} 3, \mathrm{H} 4, \mathrm{H} 7$ et $\mathrm{H} 13$ ) [5]. La mesure de l'activité enzymatique de la TK des HSV vis-à-vis des nucléosides naturels que sont la désoxyguanosine $(\mathrm{d} G)$ et la désoxythymidine (dT), et des analogues nucléosidiques comme l'ACV et la BVdU, a montré, dans une étude relativement ancienne, une spécificité de substrat plus large de l'enzyme virale par rapport à celle des TK cellulaires hTK1 et hTK2, h pour "human", présentes au niveau cytosolique et mitochondrial, respectivement (Tableau 2) [5,11-20]. II n'existe pas de données plus récentes sur cette spécificité de substrat. Les hTK1 et hTK2 ne sont pas capables d'utiliser comme substrat accepteur de phosphate la dG ou son analogue l'ACV [21]. 


\section{Activation des analogues de désoxyguanosine}

L'ACV et le PCV sont spécifiquement primophosphorylés par la TK virale (Figure 2) $[5,22]$. Les deux phosphorylations suivantes, permettant d'obtenir la forme active de ces deux antiviraux, sont assurées par la guanylate kinase (ou guanosine monophosphate kinase, GMPK) et la nucléoside diphosphate kinase A (NDPK-A) cellulaires. Les formes triphosphates actives, ACV-TP et PCV-TP, sont alors reconnues par I'ADN polymérase virale et incorporées dans I'ADN viral en cours de synthèse $[2,5]$. Le VACV et le FCV, prodrogues de l'ACV et du PCV respectivement, sont hydrolysées par des estérases cellulaires pour libérer secondairement le principe actif. Dans le cas du FCV, une fois le produit 6-désoxy-PCV obtenu par hydrolyse via une estérase cellulaire, une étape d'oxydation effectuée par l'aldéhyde oxydase cellulaire permet d'obtenir le PCV [23,24].

\section{Activation de la BVdU}

La BVdU est un analogue de la désoxythymidine comportant une fonction bromovinyl à la place d'un groupement méthyl en position C5 de la base pyrimidique (Figure 1B) [5]. Les deux premières étapes de phosphorylation sont assurées par la TK virale (seule la TK du HSV-1 est concernée) car la TMPK cellulaire ne permet pas de phosphoryler la BVdU-MP en BVdU-DP (Figure 2). La capacité de la TK du HSV-1 à produire la forme diphosphate peut s'expliquer par un site actif plus volumineux qui permet de phosphoryler la désoxythymidine monophosphate (dTMP) en désoxythymidine diphosphate (dTDP), mais aussi la BVdU-MP en BVdU-DP.

\section{Activation du CDV}

Initialement mis sur le marché pour le traitement des rétinites associées au CMV chez les patients au stade SIDA de l'infection par le HIV, le CDV s'est révélé être également actif contre les infections par les HSV. Il présente un spectre d'action antivirale large étendu à d'autres virus à ADN bicaténaire tels que les poxvirus, les adénovirus, les polyomavirus et les papillomavirus humains [25]. Etant un analogue de nucléoside phosphonate, le CDV permet de contourner la phosphorylation par les nucléosides kinases virales, considérée comme l'étape limitante de l'activation des analogues de nucléoside. Les deux phosphorylations nécessaires à l'activation du CDV en CDV-DP (finalement la forme diphosphate active puisque le CDV a un groupe phosphonate et doit être phosphorylé deux fois pour être actif) sont assurées par la cytidine monophosphate kinase 1 (CMPK1) et la NDPK-A cellulaires (Figure 2) [3]. II est incorporé par l'ADN polymérase virale en lieu et place de la désoxycytidine triphosphate (dCTP). Un métabolite intracellulaire du CDV, la CDV-phosphocholine, obtenue via l'enzyme cellulaire choline-phosphate cytidyltransférase, permet d'augmenter sa demivie. 


\section{ADN polymérase virale : enzyme clé de la réplication du génome viral}

Il existe un groupe de protéines virales essentielles pour la réplication de l'ADN des HSV : la protéine UL9 qui assure la liaison aux origines de réplication (séquences ori), la protéine UL29 (ou ICP8) qui permet la liaison à l'ADN monocaténaire au niveau de la fourche initiale de réplication, le complexe polymérasique (UL30/UL42) et le complexe hélicase/primase associé à sa protéine accessoire (UL5/UL52 et UL8) (Figure 3). L'initiation de la réplication est ordonnée, puisque dans un premier temps, UL9, UL29 puis l'hétérotrimère UL5/UL52/UL8 se fixent au niveau de la fourche de réplication. Le complexe polymérasique est ensuite recruté et la réplication du génome viral peut alors débuter $[26,27]$. Le complexe polymérasique, indispensable à la réplication de l'ADN viral, existe sous forme d'un hétérodimère associant les sous-unités UL30 et UL42. L'ADN polymérase virale possède une activité $3^{\prime}-5^{\prime}$ exonucléasique permettant de corriger les mésappariements et de réparer l'ADN. La plupart des ADN polymérases nécessitent un facteur de processivité qui leur permet de renforcer leur association à I'ADN. Ainsi, la protéine UL42 interagit avec la partie C-terminale de la protéine UL30 créant ainsi une association enzyme/matrice ADN plus stable. Contrairement à d'autres facteurs de processivité, la protéine UL42 sous forme monomérique possède la capacité de lier directement l'ADN avec une forte affinité. La structure tridimensionnelle de cette protéine associée à I'ADN polymérase du HSV-1 a été déterminée (code Protein Data Bank [pdb] : 1DML) [28,29]. L'ADN polymérase virale (UL30) des HSV est une protéine de 1235 acides aminés (soit 3705 pb) et 1240 acides aminés (soit 3720 pb) pour HSV-1 et HSV-2, respectivement. La comparaison entre des séquences de polymérases d'eucaryotes et d'herpèsvirus a permis de mettre en évidence 9 domaines catalytiques conservés : les domaines I à III et V à VII ainsi que les domaines exonucléasiques I (Exo-I), Exo-II (aussi appelé IV) et Exo-III, situé dans le domaine $\delta$-C permettant la vérification du brin nouvellement synthétisé [30-32]. Seule la structure tridimensionnelle de l'ADN polymérase du HSV-1 a été résolue à ce jour (code pdb : 2GV9; Figure 1D) [33].

\section{Mécanisme d'action moléculaire des antiherpétiques}

Malgré leur appartenance à la même classe de molécules (analogues nucléosidiques), les formes triphosphates de l'ACV et du PCV (ACV-TP et PCV-TP) ont des mécanismes d'action distincts. L'ACVTP agit comme un terminateur de chaîne per se, alors que le PCV-TP inhibe l'élongation de la chaîne d'ADN viral après l'ajout d'un nucléotide (Nt) supplémentaire Nt+1 (Figure 4). On peut noter que ces deux molécules entrent en compétition avec la désoxyguanosine triphosphate (dGTP). Le mécanisme d'action de la BVdU-TP (analogue de la désoxythymidine triphosphate) est différent de ceux des analogues de la désoxyguanosine. La BVdU-TP entre en compétition avec la désoxythymidine triphosphate (dTTP) et son incorporation induit la synthèse de molécules d'ADN viral dont la 
structure est altérée et qui ne pourront pas être utilisées comme modèles pour la synthèse de nouveaux brins d'ADN viral, inhibant ainsi la réplication du génome viral (Figure 4) [25,34]. Le CDV-PP présente deux mécanismes d'action distincts, selon le nombre de molécules incorporées dans l'ADN viral en cours de synthèse : l'incorporation d'une seule molécule de CDV-PP altère la structure de I'ADN et ralentit la vitesse d'élongation, alors que l'incorporation de deux molécules successives de CDV-PP entraîne l'arrêt de la synthèse d'ADN (Figure 4). Au moment de l'incorporation de la forme triphosphate des nucléosides, la formation de la liaison phosphodiester génère la libération d'un groupement diphosphate lié à l'ADN viral (pyrophosphate). Le FOS (analogue du pyrophosphate) est un inhibiteur direct de I'ADN polymérase virale par interaction avec les résidus de l'enzyme qui reconnaissent les phosphates $\beta$ et $\gamma$ du désoxynucléotide triphosphate (dNTP) entrant. Une fois le nucléotide incorporé, il ne reste que le phosphate $\alpha$ et les phosphates $\beta$ et $\gamma$ sont libérés.

Différentes études ont montré que l'affinité des formes triphosphates de l'ACV, du PCV, de la BVdU, ainsi que du CDV-PP et du FOS est supérieure pour les ADN polymérases des HSV que pour les ADN polymérases cellulaires $[2,6,34-40]$. L'ACV-TP présente une constante d'inhibition $50 \%\left(K_{1}\right)$ de $3 \mathrm{nM}$ pour les ADN polymérases des HSV et de $180 \mathrm{nM}$ pour l'ADN polymérase cellulaire $\alpha$ [36]. De même, la BVdU-TP montre des affinités 10 et 50 fois supérieures pour l'ADN polymérase du HSV-1 et du HSV-2, respectivement, que pour l'ADN polymérase cellulaire $\alpha[37,39]$. La K du PCV-TP est évaluée à environ $3 \mu \mathrm{M}$ pour l'ADN polymérase des HSV, alors qu'elle est d'environ $175 \mu \mathrm{M}$ pour l'ADN polymérase cellulaire $\alpha$ [40]. Quant au CDV-PP, il permet d'inhiber les ADN polymérases du HSV-1 et du HSV-2 avec des $K_{1}$ de 0,9 $\mu \mathrm{M}$ et 1,4 $\mu \mathrm{M}$, respectivement. La $K_{1}$ du CDV-PP mesurée avec l'enzyme humaine est de $51 \mu \mathrm{M}$ [38]. 


\section{Résistance des HSV aux antiviraux}

\section{Prévalence et facteurs de risques}

En pratique clinique, il convient de traiter les formes cliniques graves d'infection herpétique en urgence par ACV administré par voie intraveineuse (IV), puis éventuellement d'instaurer un traitement de relais per os par VACV. Pour les formes moins sévères ou les traitements au long cours, il est possible de mettre en place un traitement antiviral par voie orale par VACV. Devant des lésions herpétiques persistantes et/ou une absence de régression de la charge virale alors qu'un traitement antiviral est correctement suivi depuis au moins 10 jours, la résistance clinique est évoquée [1]. Différents facteurs peuvent être responsables de l'inefficacité d'un traitement antiviral :

- Origine pharmacologique : mauvaise observance du traitement par le patient, dose insuffisante d'antiviral, catabolisme augmenté, faible concentration de l'antiviral au site de l'infection ou mauvaise diffusion de l'antiviral (liquide cérébrospinal, humeur aqueuse ...).

- Origine immunologique : patient avec une immunodépression cellulaire T sévère (patients greffés, infectés par le HIV ...).

- Origine virologique : présence de mutations de résistance au niveau des gènes viraux qui codent les enzymes cibles des antiviraux antiherpétiques, c'est-à-dire les gènes UL23 (TK) et UL30 (ADN polymérase).

Chez les individus immunocompétents, la prévalence de souches de HSV résistantes aux antiviraux, en l'occurrence l'ACV, est très faible, inférieure à $1 \%$. Une seule exception: les individus immunocompétents souffrant de kératites herpétiques récurrentes présentent un taux de résistance plus élevé pouvant atteindre $7 \%$ [1]. La prévalence varie de $2,5 \%$ à $11 \%$ chez les individus immunodéprimés (individus infectés par le HIV, greffés d'organes solides et de cellules souches hématopoiétiques). Le FOS et le CDV, alternatives thérapeutiques à l'ACV/VACV, sont également concernés mais la description de cas de résistance est beaucoup plus rare. Les facteurs favorisant la sélection et l'apparition de mutants viraux résistants sont le degré d'immunosuppression, l'utilisation prolongée de traitements prophylactiques ou curatifs anti-HSV et la présence de lésions extensives et persistantes associées à une production virale intense [1].

\section{Mécanismes moléculaires}

Dans 95\% des cas, ce sont des modifications dans le gène de la TK des HSV qui confèrent la résistance à l'ACV. Les mutations observées dans I'ADN polymérase sont, quant à elles, plus rares, mais sont impliquées dans la résistance au FOS, au CDV ou des résistances croisées à plusieurs antiviraux. Les 
modifications de la TK responsables de la résistance à l'ACV sont de deux natures. Elles consistent (i) soit en une insertion ou délétion nucléotidique au niveau de répétitions de séquences homopolymériques de guanine $(G)$, cytosine $(C)$, voire adénine $(A)$ du gène UL23, dues au dérapage de I'ADN polymérase lors de la réplication de l'ADN viral, conduisant à un décalage du cadre de lecture (frameshift) pouvant parfois induire in fine l'apparition d'un codon stop prématuré, (ii) soit en des substitutions nucléotidiques induisant un changement d'acide aminé. En ce qui concerne l'ADN polymérase virale (UL30), les cas de résistance décrits sont quasi-exclusivement le fait de changements d'acides aminés. La grande majorité des virus résistants présente des variations génétiques dans la TK virale, plus rarement au niveau de l'ADN polymérase [1,2,41-43].

Que ce soit dans la TK ou l'ADN polymérase, il existe des changements d'acides aminés qui sont sans conséquence sur la sensibilité des HSV aux antiviraux : les polymorphismes naturels. Ils sont le reflet de la diversité génétique et, contrairement aux mutations de résistance, ils sont préférentiellement situés en dehors des sites catalytiques et conservés des enzymes concernées.

\section{Mutations identifiées dans la TK}

Les changements dans la TK se traduisent par trois phénotypes distincts qui caractérisent les virus exprimant des TK mutantes: TK-altérée, TK-négative et TK-déficiente. Le phénotype TK-altérée se traduit par le changement d'acides aminés qui modifient la spécificité de substrat de l'enzyme, favorisant souvent la phosphorylation de la désoxythymidine (dT) mais perdant la capacité à phosphoryler I'ACV. Les phénotypes TK-négative et TK-déficiente résultent d'une substitution ou d'une insertion/délétion nucléotidique dans le gène de la TK qui conduit à l'expression d'une protéine virale tronquée ou ayant une activité enzymatique diminuée [5].

La Figure 5 représente le diagramme de la TK des HSV et la position des changements d'acides aminés connus associés à la résistance aux analogues de nucléosides. Les mutations identifiées dans le gène TK des HSV conduisant au phénotype TK-déficiente sont majoritaires par rapport aux changements d'acides aminés conduisant aux phénotypes TK-négative et TK-altérée. Environ 50\% des mutations sont localisées dans le « core » de la protéine (les segments de protéine entre les sites actifs mais aussi avant et après, lorsqu'ils sont repliés forment le " core » de la protéine), alors que les changements d'acides aminés identifiés dans les deux sites de liaison aux substrats donneur et accepteur de phosphate (site de liaison à l'ATP et site de liaison au nucléoside) représentent environ $40 \%$ de la totalité des mutations connues (Figure 6).

En cas de résistance, les insertions/délétions dans les répétitions d'homopolymères, conduisant à un décalage du cadre de lecture (frameshift), sont plus fréquemment identifiées (60\% à $80 \%$ ) que les mutations ponctuelles (20\% à $40 \%$ ) [42,43]. Ces modifications, produisant des protéines virales 
tronquées et inactives (TK-négative), se produisent au niveau des séquences génétiques ayant un enchaînement de C ( $n=15)$, de $G(n=9)$ ou de $A(n=5)$ comme indiquées dans le Tableau 3.

Différentes études moléculaires ont permis de caractériser certaines substitutions associées au phénotype TK-déficiente au moyen d'enzymes purifiées ou recombinantes obtenue par mutagenèse dirigée, montrant une diminution de l'activité de phosphorylation de la dT, de l'ACV ou bien du PCV $[4,44-45]$.

Quelques exemples de la littérature permettent d'illustrer la notion de TK-altérée. Les substitutions A168T (HSV-1), R177W et R223H (HSV-2), sont des variations conduisant au phénotype TK-altérée [46-51]. Andrei et al. [48] ont montré que la mutation A168T a été sélectionnée sous BVdU. Les tests de sensibilité aux antiviraux ont démontré que les clones générés restaient sensibles à l'ACV, au GCV et au PCV alors qu'ils étaient résistants à la BVdU. Des études de relation structure/fonction ont montré que l'alanine en position 168 est proche structurellement de la thymidine avec son groupement méthyl. Si on remplace l'alanine par un acide aminé dont la chaîne latérale est plus volumineuse que celle de l'alanine, on crée un encombrement stérique qui empêche la fixation des analogues de la thymidine (tels que la BVdU) mais pas de l'ACV. C'est ce qui est observé dans le cas de la mutation A168T de la TK du HSV-1 [46]. La position homologue chez le HSV-2 pour le résidu 168 du HSV-1 est le résidu 169. A cette position de la TK du HSV-2, on retrouve une sérine (un acide aminé équivalent de la thréonine) ce qui empêche la phosphorylation de la BVdU expliquant que le HSV-2 y soit naturellement résistant. Kit et coll. ont montré que la substitution R223H dans la TK du HSV-2 ne permettait pas de phosphoryler l'ACV (phénotype résistant), contrairement à la dT qui pouvait être métabolisée par l'enzyme mutante. De même, Kost et coll. ont isolé une souche résistante à l'ACV et exprimant une TK mutante (R177W HSV-2 TK) [50].

\section{Mutations identifiées dans l'ADN polymérase}

L'émergence de mutations dans le gène codant l'ADN polymérase des HSV est la deuxième voie associée à l'apparition de souches résistantes aux antiviraux. Ces mutations affectent la fonction polymérasique de l'enzyme et entraînent une diminution l'incorporation de l'ACV-TP dans I'ADN viral. La Figure 7 regroupe les changements d'acide aminé associés à la résistance identifiés jusqu'à présent pour les HSV-1 et HSV-2, qu'ils aient été décrits dans des isolats cliniques ou identifiés in vitro. On peut noter qu'une position peut être associée à différents changements d'acides aminés, tel que S724 et N815 chez HSV-1. Près des trois quarts des mutations identifiées dans l'ADN polymérase affectent la fonction polymérasique de l'enzyme, qui regroupe les domaines "Palm» (paume), "Fingers» (doigts) et "Thumb» (pouce), alors que celles apparaissant dans le domaine 3'-5' exonucléase ne représentent qu'environ $25 \%$ de la totalité des mutations (Figure 6) [2]. Certaines mutations sont associées à un profil de résistance différent, notamment de résistance croisée à l'ACV 
et au FOS, voire au CDV. Les changements d'acides aminés aux positions D780, W781, L782, M784, V813, et N815, ont été décrits comme conférant une résistance au FOS. Nous pouvons aussi citer S724N, T821M, 1922N, Y941H et R959H [52-58]. D'autres substitutions identifiées dans l'ADN polymérase de HSV-1 telles que V573M, R700M et K960R, ainsi que W998L, L1007M et I1028T, confèrent une résistance au CDV [52,53].

\section{Impact des mutations de résistance sur l'activité de l'ADN polymérase}

Le mécanisme de résistance à l'ACV a été étudié au niveau enzymologique par le groupe de Donald Coen, par la mesure de la cinétique d'incorporation de l'ACV-TP par des ADN polymérases recombinantes du HSV-1 [59]. Les substitutions E597K, R700G et R842S affectent l'affinité pour I'ACV-TP, modifiant le $\mathrm{K}_{\mathrm{M}}$ (constante de Michaelis-Menten; correspondant à la concentration en substrat pour laquelle $50 \%$ de la vitesse maximale de l'enzyme est atteinte) de 0,81 $\mu \mathrm{M}$ (ADN polymérase sauvage, souche KOS [HSV-1]) à 3,1 - 5,1 $\mu \mathrm{M}$. Cela permet d'atteindre un facteur de résistance (ratio $\mathrm{CE}_{50 \_ \text {mutant }} / \mathrm{CE}_{50 \text { _sauvage }}$ ) compris entre 2 et 20 . Un autre mécanisme conférant la résistance à l'ACV est de limiter la vitesse d'incorporation de l'ACV-TP. Les mutations R605V et F891C modifient la constante catalytique ( $k_{\text {cat }}$ ) de l'ADN polymérase sans pour autant affecter l'affinité de l'enzyme pour l'ACV-TP. La vitesse d'incorporation diminue de 37 molécules par minute à 1,8 et 0,61 molécules par minute, respectivement pour les mutations R605V et F891C, alors que l'affinité $K_{M}$ est proche de celle mesurée avec l'enzyme sauvage $(1,1-1,3 \mu \mathrm{M}$ versus $0,81 \mu \mathrm{M})$. Enfin, certaines mutations peuvent modifier à la fois l'affinité pour la molécule et la vitesse d'incorporation dans I'ADN viral. C'est le cas de S724N, Y941H et N961K, qui permettent d'atteindre un facteur de résistance de l'ordre de 4 à 8, essentiellement du fait d'un changement de l'affinité apparente pour I'ACV-TP d'un facteur 3 à 6 et de la vitesse d'incorporation d'un facteur 3,7 à 3,9. Comme cité plus haut, la résistance du HSV-1 au FOS est majoritairement observée pour les mutations localisées dans le domaine "Fingers" (D780N, W781V, L782I, M784T, V813M/A et N815L/V/Y/E/S/Q/T). R785 et K811 sont deux résidus de l'ADN polymérase du HSV-1 essentiels pour l'interaction avec le FOS. Aucune variation de ces deux positions n'a été décrite jusqu'à ce jour, probablement du fait de leur importance dans l'interaction avec le dNTP entrant [2]. En effet, l'apparition de mutations en position R785 et/ou K811 génèrerait une ADN polymérase incapable de répliquer l'ADN viral et, de ce fait, de produire des virions infectieux. Les mutations observées dans les souches de HSV-1 résistantes au FOS sont situées au niveau des positions entourant R785 et K811, et n'affectent pas de manière drastique l'incorporation de nucléosides naturels. De manière générale, les effets des mutations de résistance aux antiviraux dans I'ADN polymérase virale sont assez hétérogènes et peuvent modifier de façon drastique le fonctionnement de l'enzyme (vitesse d'incorporation de la forme triphosphate), l'affinité pour la molécule antivirale, voire les deux paramètres. 


\section{Diagnostic de la résistance des HSV aux antiviraux}

La détection de la résistance des HSV aux antiviraux est effectuée soit selon une approche phénotypique (réalisation d'un antivirogramme qui consiste en la mesure de la concentration de l'antiviral inhibant $50 \%$ de la multiplication virale $\left[\mathrm{CE}_{50}\right.$, concentration efficace $50 \%$ ] de la souche virale à tester) qui requiert d'isoler la souche virale en culture de cellules, soit selon une approche génotypique (séquençage des gènes codant les enzymes virales cibles des antiviraux). L'approche génotypique permet de s'affranchir de l'isolement viral en culture de cellules qui peut être délicat, voire impossible pour certains types de prélèvements (liquides cérébrospinaux, prélèvements oculaires ...), puisqu'il est possible de l'effectuer directement à partir des prélèvements biologiques. Le rendu de résultat en moins d'une semaine offre également la possibilité aux cliniciens de pouvoir adapter rapidement le traitement antiviral pour un patient en échec thérapeutique et chez qui une résistance à un antiviral est mise en évidence [1,42].

\section{Tests phénotypiques}

Ces tests permettent d'évaluer in vitro la sensibilité des virus aux antiviraux en mesurant l'inhibition de la multiplication virale en présence des antiviraux. La souche virale, préalablement isolée en culture cellulaire et titrée, est mise en contact avec des cellules sensibles en présence de concentrations croissantes de l'antiviral à évaluer. Après un temps d'incubation variable selon les techniques, il existe différentes possibilités pour mesurer la multiplication virale et ainsi déterminer la $\mathrm{CE}_{50}$ : lecture de l'effet cytopathique (ECP), coloration (colorant vital), détection des antigènes (immunofluorescence ou ELISA) ou quantification du génome viral par PCR (qPCR) [60-67]. La CE $\mathrm{E}_{50}$ est le plus souvent calculée à l'aide d'une courbe effet-dose (Figure 8). Les tests phénotypiques se heurtent en pratique à plusieurs écueils. Hormis la difficulté de disposer d'un isolat viral (culture impossible ou capacités réplicatives altérées du virus du fait de mutations, notamment situées dans I'ADN polymérase), ces techniques ne sont plus utilisées en pratique diagnostique classique. II s'agit souvent de techniques que seuls certains centres spécialisés réalisent encore. Afin d'éviter tout risque de mauvaise interprétation, il est nécessaire d'utiliser la dose de virus adéquate. II faut donc soit effectuer le titrage de la souche virale avant la réalisation du test de détermination de la $\mathrm{CE}_{50}$, soit utiliser la méthode d'analyse dite " en échiquier » en faisant varier à la fois la dose de virus et la concentration d'antiviral. Les tests phénotypiques existant sont très différents les uns des autres et peu standardisés. II n'est donc pas surprenant d'avoir des valeurs de $\mathrm{CE}_{50}$ très variables entre deux techniques. En effet, les valeurs de $\mathrm{CE}_{50}$ ne peuvent être comparées que lorsque le type cellulaire et la technique de révélation sont identiques. Ces différences techniques expliquent qu'il existe donc des seuils d'interprétation, en termes de concentration d'antiviral, différents selon les techniques et 
les centres qui réalisent ces tests. Enfin, le dernier inconvénient de ces tests phénotypiques concerne le délai de rendu du résultat. Ce dernier est plutôt long (environ sept à dix jours), c'est pourquoi ces tests phénotypiques ont désormais plutôt utilisés pour compléter les résultats obtenus par les tests génotypiques, notamment en cas d'identification de mutations non connues.

\section{Tests génotypiques}

Le principe de ces tests repose sur l'identification par séquençage de mutations dans les gènes viraux qui codent les enzymes impliquées dans le mécanisme d'action des antiviraux, à savoir UL23 (TK) et UL30 (ADN polymérase). Classiquement pour les HSV, c'est l'utilisation de la technique de séquençage de type Sanger qui est utilisée. Après une étape d'amplification par PCR, éventuellement suivie d'une PCR nichée pour augmenter la sensibilité, les amplicons générés sont séquencés. Les séquences nucléotidiques obtenues sont comparées à des séquences de référence et il est nécessaire d'interpréter les résultats en classant les mutations selon qu'elles sont associées à de la résistance aux antiviraux ou à du polymorphisme naturel. Pour les HSV, il n'existe pas d'algorithme officiel mis à jour régulièrement pour l'interprétation des mutations identifiées. Les seules données disponibles sont celles publiées dans la littérature scientifique. Cette approche par technique Sanger peut être quelquefois prise en défaut lorsque les charges virales sont faibles, et ne permet pas de détecter les variants minoritaires présents au sein de la population virale. Au contraire, les nouvelles technologies de séquençage de type NGS (next-generation sequencing) permettent d'améliorer grandement la détection de l'ensemble des variants viraux et, potentiellement, de détecter l'émergence de mutants résistants à des stades plus précoce de l'infection. Plusieurs publications récentes montrent que ces techniques peuvent être intéressantes pour les HSV. En effet, il est possible de mieux caractériser la population virale grâce à ces techniques. Généralement, la technique Sanger ne permet pas de détecter des mutations qui seraient présentes à un taux inférieur à $20 \%$ dans la population alors que le NGS permet la détection des variants présents en plus faible proportion en estimant la fréquence spécifique de chacun des variants. Le pyroséquençage, ou séquençage en émulsion par émission de fluorescence, est abandonné au profit du séquençage en émulsion par modification de $\mathrm{pH}$ (technologie lon Torrent, Life Technologies), plus rapide ( $4 \mathrm{~h}$ à $7 \mathrm{~h}$ versus $10 \mathrm{~h}$ à 20 h), moins coûteux et présentant une profondeur de séquençage plus importante. Néanmoins, la fiabilité du séquençage lors d'insertion ou de délétion nucléotidique n'est, là non plus, pas parfaite. C'est surtout le séquençage par émission de fluorescence sur phase solide (technique Illumina ${ }^{\circledR} /$ Solexa $^{\circledR}$ ) qui domine dans le domaine de la virologie, du fait de la plus grande simplicité et du faible taux d'erreur (environ 0,1\%) [68]. La taille relativement courte des séquences (200 pb environ) est compensée par le grand nombre de séquences produites. La durée de l'analyse reste assez longue (30 h à 100 h), mais le coût est relativement raisonnable. Cette technique permet ainsi 
une analyse fine des populations virales. Enfin, des technologies dites de troisième génération voient actuellement le jour, mais restent d'utilisation plus limitée. On citera, par exemple, le séquençage $d^{\prime}$ une molécule unique en temps réel (technologie de Pacific Biosciences ${ }^{\circledR}$ et Oxford Nanopore ${ }^{\circledR}$ ) permettant d'obtenir une longueur de séquence importante (>1000 pb), mais avec un taux d'erreurs non négligeable et un coût important [69].

\section{Identification de nouvelles mutations de résistance aux antiviraux}

\section{Tests enzymatiques fonctionnels}

Le développement de méthodes simples permettant de caractériser les mutations responsables de la résistance des HSV aux antiviraux est d'un grand intérêt. Les premiers travaux sur l'étude de l'activité fonctionnelle de la TK virale ont été publiés dès 1986. Funderburgh et coll. ont montré l'existence de souches de HSV-1 isolées de patients atteints de kératites herpétiques traités sans succès par l'iododésoxyuridine (IdU), un analogue de la dT. Les isolats cliniques ont pu être mis en culture sur une lignée cellulaire B82 d’origine murine déficitaire en TK. Puis, l'activité de phosphorylation de la TK virale a été mesurée vis-à-vis de la dT et de l'IdU radiomarquées après une réaction kinase réalisée sur un échantillon du lysat cellulaire [70]. Au début des années 2000, des méthodes similaires pour l'étude fonctionnelle de la TK virale in vitro ont été réalisées à partir de surnageants de cultures cellulaires déficitaires en TK et infectées par des isolats de HSV-2 provenant d'un nouveau-né atteint d'herpès néonatal [71] et par des souches de HSV-1 résistantes à l'ACV sélectionnés in vitro [72]. Dans la continuité de ces premiers travaux, des systèmes d'expression de la TK du HSV-1 in vitro (en bactéries sous induction par l'isopropyl-beta-D-thiogalactopyranoside [IPTG] ou en lysat de réticulocytes de lapin) suivis d'une étude de l'activité enzymatique de phosphorylation de la dT par la TK virale ont été mis au point pour la caractérisation du rôle précis de certaines mutations [73-75]. Toutefois, ces méthodes, qui permettent d'associer une mutation à un profil phénotypique de type TK-altérée voire TK-déficiente, utilisaient la radioactivité pour mesurer l'activité de phosphorylation de la TK du HSV-1 uniquement. Un autre système original d'expression du gène de la TK du HSV-1 dans le parasite Leishmania, normalement dépourvu d'activité TK endogène, a été mis au point pour discriminer de façon indirecte les mutations de la TK conférant la résistance à l'ACV des mutations impliquées dans le polymorphisme naturel [76]. Plus récemment, la TK sauvage et des TK mutées du HSV-1 ont été exprimé dans des cellules 293T (cellules embryonnaires humaines) après transfection en présence d'un virus HSV-1 TK-déficient et de concentrations croissantes d'ACV. Par la suite, la quantification par PCR en temps réel de la multiplication virale permettait de déterminer la $C_{50}$ de la souche testée vis-à-vis de l'ACV. L'avantage de ce système est de pouvoir tester d'autres molécules antivirales que I'ACV [77]. D'autres équipes ont mis au point des méthodes d'étude de l'activité fonctionnelle de la TK des HSV 
sans radioactivité, mais en utilisant la chromatographie liquide haute performance (CLHP), la spectrophotométrie de masse MALDI-TOF, la chimioluminescence ou la révélation par ELISA [78-82].

\section{Utilisation des virus recombinants}

Traditionnellement, le rôle putatif de mutations dans la résistance aux antiviraux était confirmé par des expériences de transfert de marqueur. Une mutation précise était transférée dans un fond génétique de virus sensible aux antiviraux par recombinaison homologue [32,83-87]. Expérimentalement, il fallait transfecter des cellules permissives avec, simultanément, le génome viral intact d'une souche de référence et le gène contenant la mutation de résistance suspectée à échanger par recombinaison homologue. La sélection du virus recombinant était alors réalisée grâce à un antiviral. Une autre approche consistait à générer des virus recombinants en co-transfectant des cosmides et des plasmides chevauchants dans des cellules permissives [87-89]. Plus récemment, la solution permettant de facilement créer des virus recombinants est apparue en détournant la machinerie bactérienne. L'utilisation de virus recombinants produits en utilisant un système de chromosome artificiel bactérien (bacterial artificial chromosome, BAC) a été développé récemment pour HSV dans le cadre de la résistance aux antiviraux [90-92] sur le modèle des travaux effectués sur le cytomégalovirus (CMV) [93-96]. En effet, le clonage des génomes viraux entiers dans des vecteurs de type BAC est possible et permet de manipuler ces génomes en utilisant les systèmes de recombinaison présents chez les bactéries, notamment Escherichia coli. La reconstitution des particules virales infectieuses mutantes est ensuite obtenue après transfection de cellules de mammifères permissives. II suffit ensuite de réaliser des tests phénotypiques de recherche de résistance aux antiviraux (antivirogramme) pour clarifier le rôle des mutations d'intérêt. Cette technologie, qui permet d'étudier des mutations situées dans le gène de la TK et/ou dans le gène de I'ADN polymérase, constitue dorénavant la méthode de référence.

\section{Perspective de nouveaux antiviraux : les inhibiteurs du complexe hélicase-primase}

Le complexe hélicase/primase (UL5/UL52) associé à sa protéine accessoire (UL8) joue un rôle indispensable dans la réplication de I'ADN viral puisqu'il permet de dérouler l'ADN viral double brin (activité de l'hélicase) et de produire les amorces nécessaires à l'initiation de la réplication par l'ADN polymérase (activité de la primase) (Figure 3). Les hélicases jouent un rôle central, non seulement dans la mise en place de la boucle de réplication, mais aussi dans la régulation de la dynamique et de la coordination du processus de réplication du génome. Les primases constituent une classe majeure de partenaires d'interaction avec l'hélicase. Elles synthétisent les amorces complémentaires des brins d'ADN en cours d'élongation permettant ainsi une action optimale de l'ADN polymérase [97]. La protéine accessoire facilite le recrutement du complexe polymérasique (UL30/UL42) (Marsden, 
McLean et al. 1997). Ce complexe apparaît donc comme une cible thérapeutique intéressante. Encore au stade des essais cliniques, les inhibiteurs du complexe hélicase/primase (IHP) que sont l'aménamévir (AMV) et le pritélivir (PTV) s'avèrent être de nouvelles molécules très prometteuses [98]. A ce jour, le PTV a montré son efficacité, au cours d'un essai clinique de phase 2 , dans le traitement de l'herpès génital [99]. D'autres essais cliniques de phase 2 sont en attente de résultats ou en cours pour le PTV dans le cadre du traitement de l'herpès labial sous forme topique, ou du traitement des infections cutanéomuqueuses par HSV résistantes à l'ACV chez les patients immunodéprimés. L'AMV, pour lequel sont attendu les résultats d'un essai clinique de phase 3 dans le cadre du traitement des infections herpétiques labiales et génitales, a d'ores et déjà été autorisé au Japon en 2017 pour le traitement du zona. Ces molécules ont démontré lors d'études cliniques une très bonne efficacité dans le traitement des lésions herpétiques. Il a été observé une activité du PTV in vitro supérieure à celle de l'ACV [100]. L'AMV présente une $C_{50}$ moyenne de 0,036 $\mu \mathrm{M}$ pour le HSV-1 et une activité 14 fois supérieure à celle du VACV [101]. Leur principal atout est de rester actif sur les virus résistants à l'ACV [102]. De plus, elles possèdent une biodisponibilité de l'ordre de 40\% pour l'AMV et de plus de $60 \%$ pour le PTV, permettant donc leur administration par voie orale $[103,104]$. D'autres avantages ont été décrits : une activité synergique avec l'ACV a été décrite, ainsi qu'une excellente diffusion au travers de la barrière hémato-encéphalique [102-105]. Ces caractéristiques sont encourageantes pour le traitement des encéphalites herpétiques, et notamment celles dues à une souche de HSV résistante à l'ACV. Malheureusement des mutations conférant une résistance à ces IHP ont déjà été identifiées, principalement in vitro [100,106-107]. 


\section{Conclusion}

Les infections par les HSV constituent un important problème de santé, notamment parmi les populations de patients immunodéprimés, et ce malgré la disponibilité d'une molécule très active et quasiment atoxique : I'ACV. II y a, à ce jour, peu de molécules alternatives à l'ACV disponibles en France ayant une autorisation de mise sur le marché (AMM) : ce sont toutes des inhibiteurs de l'ADN polymérase virale. En France, c'est classiquement le FOS qui est utilisé en deuxième ligne pour remplacer I'ACV, mais, malheureusement, il possède un fort pouvoir néphrotoxique. De plus, la résistance des HSV antiviraux peut également complexifier la prise en charge thérapeutique des patients concernés. Le développement de nouveaux antiviraux est fondamental et doit absolument cibler des enzymes virales différentes, afin d'éviter les problèmes de résistance croisée et de permettre de réaliser des associations potentiellement synergiques, tout en possédant un minimum d'effets indésirables. Ainsi, la découverte récente des inhibiteurs du complexe hélicase-primase constitue une avancée majeure pour espérer prochainement compléter l'arsenal thérapeutique des antiviraux anti-HSV. 


\section{Légendes des figures}

Figure 1. Structure chimique des antiviraux utilisés contre les infections par les virus herpes simplex 1 et 2 (HSV-1 et HSV-2)

Les analogues nucléosidiques (panel A) qu'ils soient des analogues de désoxyguanosine (aciclovir $[A C V]$, valaciclovir [VACV], penciclovir [PCV], famciclovir [FCV]) ou de désoxythymidine (brivudine [BVdU]) ou l'analogue nucléosidique phosphonate de type désoxycytidine monophosphate, dCMP (cidofovir [CDV] ; panel B) constituent avec l'analogue de pyrophosphate (foscarnet [FOS] ; panel C) l'ensemble des molécules anti-HSV disponibles.

Structures tridimensionnelles de la thymidine kinase (TK, code Protein Data Bank [pdb] : 2KI5), formant un complexe binaire avec l'ACV, et de l'ADN polymérase (code pdb : 2GV9) de HSV-1 qui sont les protéines clés de la stratégie antiherpétique (panel D). Dans la structure de l'ADN polymérase virale, les régions $3^{\prime}-5^{\prime}$ exonucléase et les domaines " Finger " sont mis en évidence en orange et bleu, respectivement. Ces deux domaines clés représentent les deux fonctions assurées par l'enzyme virale, à savoir l'activité de correction dite de " proofreading » et l'activité polymérase. Les images des structures tridimensionnelles ont été générées avec le software PyMolm ${ }^{\mathrm{TM}}$.

Figure 2. Modes d'activation des analogues de nucléos(t)ides

ACV : aciclovir ; BVdU : brivudine; CDV : cidofovir ; CMPK1 : cytidine monophosphate kinase 1 ; GMPK : guanylate kinase; FCV : famciclovir; FOS: foscarnet; NDPK-A : nucléoside diphosphate kinase A ; PCV : penciclovir; TK: thymidine kinase ; VACV : valaciclovir; -MP/-DP/-TP : forme mono/di/tri-phosphate.

Figure 3. Boucle de réplication du génome des HSV impliquant les complexes polymérasique (UL30/UL42) et hélicase-primase (UL5/UL52/UL8)

Les protéines virales essentielles pour la formation de la boucle de réplication du génome viral à proprement parlé sont : la protéine UL29 (ou ICP8) qui permet la liaison à l'ADN monocaténaire au niveau de la fourche initiale de réplication, le complexe polymérasique (UL30/UL42) et le complexe hélicase/primase associé à sa protéine accessoire (UL5/UL52 et UL8). L'initiation de la réplication est ordonnée, puisque dans un premier temps, UL9 (protéine de liaison aux séquences ori du génome viral pour initier la réplication), UL29 (ICP8) puis l'hétérotrimère UL5/UL52/UL8 se fixent au niveau de la fourche de réplication. Le complexe polymérasique est ensuite recruté et la réplication du génome viral peut alors débuter (Figure adaptée de [26]). 


\section{Figure 4. Modes d'action des analogues de nucléos(t)ides}

Une fois activés, ces analogues sont incorporés par l'ADN polymérase (ADNpol) dans l'ADN viral en élongation. Ils entrent en compétition avec les désoxyribonucléosides triphosphates (dCTP, dGTP et dTTP), naturels et, en fonction de la nature de leurs modifications physicochimiques, leurs effets sur l'élongation de l'ADN viral peuvent varier de la terminaison de chaîne à la diminution de la vitesse d'élongation, ainsi qu'à la production de génomes viraux impropres à la réplication du génome viral. ACV : aciclovir; BVdU : brivudine; CDV : cidofovir ; FOS : foscarnet; $\mathrm{Nt}$ : nucléotide ; PCV : penciclovir ; -DP/-TP : forme di/tri-phosphate.

Figure 5. Diagrammes de la thymidine kinase des HSV-1 et HSV-2 et position des changements d'acides aminés associés à la résistance aux antiherpétiques

Les changements d'acides aminés notés en bleu sont associés au phénotype "TK-négative ». Les régions conservées parmi les herpèsvirus sont définis par des boîtes blanches (site de liaison à l'ATP [adénosine triphosphate], site de liaison au nucléoside et autres domaines conservés). Les substitutions d'acides aminés localisées dans les deux sites de liaison aux nucléosides/nucléotides sont minoritaires par rapport à ceux présents dans le « core " de la TK virale, formé par des segments protéiques en amont et en aval des deux sites de liaison.

Figure 6. Distribution des changements d'acides aminés identifiés dans les domaines fonctionnels de la TK et de l'ADN polymérase du HSV-1 et du HSV-2 (Figure adaptée de [2,4])

Figure 7. Diagrammes de l'ADN polymérase des HSV-1 et HSV-2 et position des changements d'acides aminés associés à la résistance aux antiherpétiques

Les régions conservées de l'ADN polymérase au sein des herpèsvirus (I - VII et $A)$ sont représentées par des boîtes blanches. La position de chaque boîte au sein de la chaîne polypeptidique est indiquée par des chiffres en italique.

Figure 8. Détermination de la concentration efficace $50 \%\left(\mathrm{CE}_{50}\right)$ et de la concentration cytotoxique $50 \%\left(\mathrm{CC}_{50}\right)$ d'un antiviral à partir des courbes effet-dose

La courbe effet-dose de l'antiviral (courbe rouge) en forme de sigmoïde est tracée en représentant le pourcentage de production virale par rapport au témoin sans antiviral (témoin virus) pour chaque dose d'antiviral. On peut ensuite calculer la $\mathrm{CE}_{50}$, avec précision sur la partie linéaire de la pente. On peut calculer de la même façon la $\mathrm{CC}_{50}$ sur la courbe effet-dose de l'antiviral résultant du test de cytotoxicité (courbe bleue). 
Tableaux

Tableau 1. Molécules antivirales actives sur les virus herpes simplex

\begin{tabular}{lllll}
\hline Classe & Molécule & Abréviation & Modifications/dérivés & Métabolisations requises \\
\hline Analogue de & Aciclovir & ACV & Analogue de désoxyguanosine (dG) & Phosphorylation-(x 3)* \\
nucléoside & Valaciclovir & VACV & Ester de valine d'ACV & Hydrolyse/Phosphorylation-(x 3)* \\
& Penciclovir & PCV & Analogue de désoxyguanosine (dG) & Phosphorylation (x 3)* \\
& Famciclovir & FCV & Diacétyl ester de 6-désoxy-PCV & Hydrolyse/Oxydation/Phosphorylation-(x3)* \\
& Brivudine & BVdU & Analogue de désoxythymidine (dT) & Phosphorylation-(x 3)* \\
Analogue de & Cidofovir & CDV & Analogue de désoxycytidine & Phosphorylation-(x 2) \\
nucléotide & & & monophosphate (dCMP) & Aucune \\
Analogue de & Foscarnet & FOS & Analogue de pyrophosphate &
\end{tabular}

* 3 étapes de phosphorylation sont nécessaires pour obtenir la forme active. 2 étapes de phosphorylation sont requises pour produire la forme active. Toutes les molécules sont actives vis-à-vis du HSV-1 et du HSV-2 sauf la BVdU qui est active uniquement vis-à-vis du HSV-1. 
Tableau 2. Activité enzymatique des thymidines kinases (TK) humaines hTK1 et hTK2 et virale HSV-1 TK vis-à-vis des molécules dT, dG, ACV et BVdU

\begin{tabular}{lccc}
\hline & \multicolumn{3}{c}{ Activité enzymatique } \\
\cline { 2 - 4 } & hTK1 & hTK2 & HSV-1 TK \\
\hline dT & $8 \times 10^{6} \mathrm{M}^{-1} \cdot \mathrm{s}^{-1}$ & $9 \times 10^{5} \mathrm{M}^{-1} \cdot \mathrm{s}^{-1}$ & $1,2 \times 10^{6} \mathrm{M}^{-1} \cdot \mathrm{s}^{-1}$ \\
dG & {$[11,12]$} & {$[14]$} & {$[13,18]$} \\
& Non détectée & Non détectée & $5 \times 10^{4} \mathrm{M}^{-1} \cdot \mathrm{s}^{-1}$ \\
ACV & {$[14]$} & {$[14]$} & {$[15]$} \\
& Non détectée & Non détectée & $36-300 \mathrm{M}^{-1} \cdot \mathrm{s}^{-1}$ \\
BVdU & {$[5]$} & {$[5]$} & {$[13,16,17]$} \\
& Non détectée & $2 \times 10^{5} \mathrm{M}^{-1} \cdot \mathrm{s}^{-1}$ & $1,0 \times 10^{6} \mathrm{M}^{-1} \cdot \mathrm{s}^{-1}$ \\
& {$[5]$} & {$[14,19,20]$} & {$[15,19]$}
\end{tabular}

hTK1 est trouvée au niveau cytosolique alors que hTK2 est localisée au niveau mitochondrial. ACV : aciclovir ; BVdU : brivudine ; dG : désoxyguanosine ; dT : désoxythymidine. . Unité $\mathrm{M}^{-1} \cdot \mathrm{s}^{-1}$ où $\mathrm{M}$ représente la concentration molaire (moles/litre) et $\mathrm{s}$ le temps exprimé en seconde. Les références bibliographiques concernées sont notées dans le tableau : [5, 11-20]. 
Tableau 3. Insertions et délétions nucléotidiques répertoriées dans le gène de la thymidine kinase (TK) des virus herpes simplex 1 et 2 (HSV-1 et HSV-2) conduisant à un décalage du cadre de lecture (frameshift) et conférant une résistance à l'aciclovir (ACV)

\begin{tabular}{|c|c|c|c|c|}
\hline \multirow[b]{2}{*}{ Insertions } & \multicolumn{2}{|c|}{ HSV-1 } & \multicolumn{2}{|c|}{ HSV-2 } \\
\hline & Nts133-136 & AAAA & Nts215-217 & $\mathrm{CCC}$ \\
\hline & Nts180-183 & GGGG & Nts219-222 & GGGG \\
\hline & Nts184-187 & AAAA & Nts246-249 & $\mathrm{CCCC}$ \\
\hline & Nts430-436 & GGGGGGG & Nts279-280 & GGGGG \\
\hline & Nts455-458 & $\mathrm{CCCC}$ & Ins428 & G \\
\hline & Nts460-464 & $\mathrm{CCCCC}$ & Nts433-439 & GGGGGGG \\
\hline & Nts548-553 & $\mathrm{cccccc}$ & Nts463-467 & $\mathrm{CCCCC}$ \\
\hline & Nts615-619 & GGGGG & Nts482-485 & TTTT \\
\hline & Nts666-669 & $\mathrm{CCCC}$ & Nts519-521 & $\mathrm{CCC}$ \\
\hline & Nts878-880 & GGG & Nts551-556 & $\mathrm{cccccc}$ \\
\hline & Nts896-900 & $\mathrm{ccccc}$ & Nts586-590 & $\mathrm{ccccc}$ \\
\hline & & & Ins626-627 & TT \\
\hline & & & Nts779-782 & GGGG \\
\hline & & & Nts792-796 & GGGGG \\
\hline & & & Nts809-812 & $\mathrm{CCCC}$ \\
\hline & & & Nts816-819 & $\mathrm{CCCC}$ \\
\hline \multirow[t]{5}{*}{ Délétions } & Del227 & $A$ & Del227 & $A$ \\
\hline & Del880 & G & Del306 & $\mathrm{C}$ \\
\hline & Del884 & G & & \\
\hline & Del1061-1064 & $\mathrm{CcCCC}$ & & \\
\hline & Del1065 & A & & \\
\hline
\end{tabular}

Del : délétion ; Ins : insertion ; Nts : nucléotides. 


\section{Références bibliographiques}

1. Piret J, Boivin G. Antiviral drug resistance in herpesviruses other than cytomegalovirus. Rev Med Virol, 2014;24:186-218.

2. Topalis D, Gillemot S, Snoeck R, Andrei G. Distribution and effects of amino acid changes in drugresistant alpha and beta herpesviruses DNA polymerase. Nucleic Acids Res, 2016, 44(20): p. 95309554.

3. Kimberlin DW, Whitley RJ. Antiviral therapy of HSV-1 and -2. In: Arvin A, Campadelli-Fiume G, Mocarski E, et al., editors. Human Herpesviruses: Biology, Therapy, and Immunoprophylaxis. Cambridge: Cambridge University Press; 2007. Chapter 64. Available from: https://www.ncbi.nlm.nih.gov/books/NBK47444/

4. Topalis D, Gillemot S, Snoeck R, Andrei G. Thymidine kinase and protein kinase in drug-resistant herpesviruses: Heads of a Lernaean Hydra. Drug Resist Updat, 2018, 37: p. 1-16.

5. Deville-Bonne D, El Amri C, Meyer P, Chen Y, Agrofoglio LA, Janin J. Human and viral nucleoside/nucleotide kinases involved in antiviral drug activation: structural and catalytic properties. Antiviral Res, 2010, 86(1): p. 101-120.

6. Allaudeen HS, Kozarich JW, Bertino JR, De Clercq E. On the mechanism of selective inhibition of herpesvirus replication by (E)-5-(2-bromovinyl)-2'-deoxyuridine. Proc Natl Acad Sci U S A, 1981, 78(5): p. $2698-702$.

7. Snoeck R. Antiviral therapy of herpes simplex. Int J Antimicrob Agents, 2000. 16(2): p. 157-9.

8. Meier P, Dautheville-Guibal S, Ronco PM, Rossert J. Cidofovir-induced end-stage renal failure. Nephrol Dial Transplant, 2002, 17(1): p. 148-9.

9. Ortiz A, Justo P, Sanz A, Melero R, Caramelo C, Guerrero MF, Strutz F, Muller G, Barat A, Egido J. Tubular cell apoptosis and cidofovir-induced acute renal failure. Antivir Ther, 2005. 10(1): p. 185-90.

10. Zedtwitz-Liebenstein K, Presterl E, Deviatko E, Graninger W. Acute renal failure in a lung transplant patient after therapy with cidofovir. Transpl Int, 2001, 14(6): p. 445-6.

11. Munch-Petersen B, Cloos L, Tyrsted G, Eriksson S. Diverging substrate specificity of pure human thymidine kinases 1 and 2 against antiviral dideoxynucleosides. J Biol Chem. 1991;266(14):90329038.

12. Eriksson S, Munch-Petersen B, Johansson K, Eklund H. Structure and function of cellular deoxyribonucleoside kinases. Cell Mol Life Sci. 2002;59(8):1327-1346.

13. Kokoris MS, Black ME. Characterization of herpes simplex virus type 1 thymidine kinase mutants engineered for improved ganciclovir or acyclovir activity. Protein Sci. 2002;11(9):2267-2272.

14. Wang J, Choudhury D, Chattopadhyaya J, Eriksson S. Stereoisomeric selectivity of human deoxyribonucleoside kinases. Biochemistry. 1999;38(51):16993-16999. 
15. Fyfe JA, Keller PM, Furman PA, Miller RL, Elion GB. Thymidine kinase from herpes simplex virus phosphorylates the new antiviral compound, 9-(2-hydroxyethoxymethyl)guanine. J Biol Chem. 1978;253(24):8721-8727.

16. Schelling P, Folkers G, Scapozza L. A spectrophotometric assay for quantitative determination of kcat of herpes simplex virus type 1 thymidine kinase substrates. Anal Biochem. 2001;295(1):82-87.

17. Balzarini J, Liekens S, Esnouf R, De Clercq E. The A167Y mutation converts the herpes simplex virus type 1 thymidine kinase into a guanosine analogue kinase. Biochemistry. 2002;41(20):65176524.

18. Pilger BD, Perozzo R, Alber F, Wurth C, Folkers G, Scapozza L. Substrate diversity of herpes simplex virus thymidine kinase. Impact of the kinematics of the enzyme. J Biol Chem. 1999;274(45):31967-31973.

19. Cheng YC, Dutschman G, De Clercq E, et al. Differential affinities of 5-(2-halogenovinyl)-2'deoxyuridines for deoxythymidine kinases of various origins. Mol Pharmacol. 1981;20(1):230-233.

20. Verri A, Priori G, Spadari S, Tondelli L, Focher F. Relaxed enantioselectivity of human mitochondrial thymidine kinase and chemotherapeutic uses of L-nucleoside analogues. Biochem J. 1997;328 ( Pt 1)(Pt 1):317-320.

21. Fyfe JA. Differential phosphorylation of (E)-5-(2-bromovinyl)-2'-deoxyuridine monophosphate by thymidylate kinases from herpes simplex viruses types 1 and 2 and varicella zoster virus. Mol Pharmacol, 1982, 21(2): p. 432-7.

22. Vogt J, Perozzo R, Pautsch A, Prota A, Schelling P, Pilger B, Folkers G, Scapozza L, Schulz GE. Nucleoside binding site of herpes simplex type 1 thymidine kinase analyzed by X-ray crystallography. Proteins, 2000, 41(4): p. 545-53.

23. Clarke SE, Harrell AW, Chenery RJ. Role of aldehyde oxidase in the in vitro conversion of famciclovir to penciclovir in human liver. Drug Metab Dispos, 1995. 23(2): p. 251-4.

24. Rashidi MR, Smith JA, Clarke SE, Beedham C. In vitro oxidation of famciclovir and 6deoxypenciclovir by aldehyde oxidase from human, guinea pig, rabbit, and rat liver. Drug Metab Dispos, 1997, 25(7): p. 805-13.

25. De Clercq E. The Holy Trinity: the acyclic nucleoside phosphonates. Adv Pharmacol, 2013. 67: p. 293-316.

26. Coen DM and Schaffer PA. Antiherpesvirus drugs: a promising spectrum of new drugs and drug targets. Nat Rev Drug Discov. 2003;2(4): 278-288.

27. Weller SK and Coen DM. Herpes simplex viruses: mechanisms of DNA replication. Cold Spring Harb Perspect Biol. 2012;4(9): a013011. 
28. Zuccola HJ, Filman DJ, Coen DM, Hogle JM. The crystal structure of an unusual processivity factor, herpes simplex virus UL42, bound to the $\mathrm{C}$ terminus of its cognate polymerase. Mol Cell. 2000;5(2):267-278.

29. Chaudhuri M, Song L, Parris DS. The herpes simplex virus type 1 DNA polymerase processivity factor increases fidelity without altering pre-steady-state rate constants for polymerization or excision. J Biol Chem. 2003;278(11):8996-9004.

30. Tsurumi T, Maeno K, Nishiyama Y. A single-base change within the DNA polymerase locus of herpes simplex virus type 2 can confer resistance to aphidicolin. J Virol. 1987;61(2):388-394.

31. Zhang J, Chung DW, Tan CK, Downey KM, Davie EW, So AG. Primary structure of the catalytic subunit of calf thymus DNA polymerase delta: sequence similarities with other DNA polymerases. Biochemistry. 1991;30(51):11742-11750.

32. Hwang $\mathrm{CB}$, Ruffner $\mathrm{KL}$, Coen $\mathrm{DM}$. A point mutation within a distinct conserved region of the herpes simplex virus DNA polymerase gene confers drug resistance. J Virol. 1992;66(3):1774-1776.

33. Liu S, Knafels JD, Chang JS, et al. Crystal structure of the herpes simplex virus 1 DNA polymerase. J Biol Chem. 2006;281(26):18193-18200

34. Mancini WR, De Clercq E, and Prusoff WH. The relationship between incorporation of E-5-(2Bromovinyl)-2'-deoxyuridine into herpes simplex virus type 1 DNA with virus infectivity and DNA integrity. J Biol Chem. 1983;258(2): p. 792-5.

35. Allaudeen HS, Descamps J, Sehgal RK. Mode of action of acyclovir triphosphate on herpesviral and cellular DNA polymerases. Antiviral Res. 1982;2(3): p. 123-33.

36. Derse D, Cheng YC, Furman PA, St Clair MH, Elion GB. Inhibition of purified human and herpes simplex virus-induced DNA polymerases by 9-(2-hydroxyethoxymethyl)guanine triphosphate. Effects on primer-template function. J Biol Chem. 1981;256(22): p. 11447-51.

37. Frank KB, Chiou JF, Cheng YC.Interaction of DNA polymerase and nucleotide analog triphosphates. Adv Enzyme Regul. 1985; 24: p. 377-84.

38. Ho HT, Woods KL, Bronson JJ, De Boeck H, Martin JC, Hitchcock MJ. Intracellular metabolism of the antiherpes agent (S)-1-[3-hydroxy-2-(phosphonylmethoxy)propyl]cytosine. Mol Pharmacol. 1992; 41(1): p. 197-202.

39. Ono K, Nakane H, De Clercq E. Potent inhibitory effects of the 5'-triphosphates of (E)-5-(2bromovinyl)-2'-deoxyuridine and (E)-5-(2-bromovinyl)-1-beta-D-arabinofuranosyluracil on DNA polymerase gamma. Eur J Biochem. 1990;190(3): p. 463-7.

40. Ono N, Iwayama S, Suzuki K, Sekiyama T, Nakazawa H, Tsuji T, Okunishi M, Daikoku T, Nishiyama Y. Mode of action of (1'S,2'R)-9-[[1',2'-bis(hydroxymethyl) cycloprop-1'-yl]methyl]guanine (A-5021) against herpes simplex virus type 1 and type 2 and varicella-zoster virus. Antimicrob Agents Chemother. 1998;42(8): p. 2095-102. 
41. Sauerbrei A, Bohn-Wippert K, Kaspar M, Krumbholz A, Karrasch M, Zell R. Database on natural polymorphisms and resistance-related non-synonymous mutations in thymidine kinase and DNA polymerase genes of herpes simplex virus types 1 and 2. J Antimicrob Chemother. 2016;71(1): p. 616.

42. Burrel S, Aime C, Hermet L, Ait-Arkoub Z, Agut H, Boutolleau D. Surveillance of herpes simplex virus resistance to antivirals: a 4-year survey. Antiviral Res. 2013;100:365-72.

43. Frobert E, Burrel S, Ducastelle-Lepretre S, Billaud G, Ader F, Casalegno JS, Nave V, Boutolleau D, Michallet M, Lina B, Morfin F. Resistance of herpes simplex viruses to acyclovir: an update from a ten-year survey in France. Antiviral Res. 2014 Nov;111:36-41.

44. Degreve B, Esnouf R, De Clercq E, Balzarini J. Mutation of $G \ln 125$ to Asn selectively abolishes the thymidylate kinase activity of herpes simplex virus type 1 thymidine kinase. Mol Pharmacol. 2001;59(2): p. 285-93.

45. Hinds TA, Compadre C, Hurlburt BK, Drake RR. Conservative mutations of glutamine-125 in herpes simplex virus type 1 thymidine kinase result in a ganciclovir kinase with minimal deoxypyrimidine kinase activities. Biochemistry. 2000;39(14): p. 4105-11.

46. Kussmann-Gerber S, Kuonen O, Folkers G, Pilger BD, Scapozza L. Drug resistance of herpes simplex virus type 1-structural considerations at the molecular level of the thymidine kinase. Eur J Biochem. 1998;255(2): p. 472-81.

47. Balzarini J, Liekens S, Esnouf R, De Clercq E. The A167Y mutation converts the herpes simplex virus type 1 thymidine kinase into a guanosine analogue kinase. Biochemistry. 2002;41(20): p. 651724.

48. Andrei G, Balzarini J, Fiten P, De Clercq E, Opdenakker G, Snoeck R. Characterization of herpes simplex virus type 1 thymidine kinase mutants selected under a single round of high-dose brivudin. $J$ Virol. 2005;79(9): p. 5863-9.

49. Kit S, Sheppard M, Ichimura H, Nusinoff-Lehrman S, Ellis MN, Fyfe JA, Otsuka H. Nucleotide sequence changes in thymidine kinase gene of herpes simplex virus type 2 clones from an isolate of a patient treated with acyclovir. Antimicrob Agents Chemother. 1987;31(10): p. 1483-90.

50. Kost RG, Hill EL, Tigges M, Straus SE. Brief report: recurrent acyclovir-resistant genital herpes in an immunocompetent patient. N Engl J Med. 1993;329(24): p. 1777-82.

51. Balzarini J, Liekens S, Solaroli N, El Omari K, Stammers DK, and Karlsson A. Engineering of a single conserved amino acid residue of herpes simplex virus type 1 thymidine kinase allows a predominant shift from pyrimidine to purine nucleoside phosphorylation. J Biol Chem. 2006;281(28): p. 19273-9.

52. Andrei G, Fiten P, Froeyen M, De Clercq E, Opdenakker G, Snoeck R. DNA polymerase mutations in drug-resistant herpes simplex virus mutants determine in vivo neurovirulence and drug-enzyme interactions. Antivir Ther. 2007;12(5): p. 719-32. 
53. Andrei G, Snoeck R, De Clercq E, Esnouf R, Fiten P, Opdenakker G. Resistance of herpes simplex virus type 1 against different phosphonylmethoxyalkyl derivatives of purines and pyrimidines due to specific mutations in the viral DNA polymerase gene. J Gen Virol. 2000;81(Pt 3): p. 639-48.

54. Bestman-Smith J and Boivin G. Drug resistance patterns of recombinant herpes simplex virus DNA polymerase mutants generated with a set of overlapping cosmids and plasmids. J Virol. 2003;77(14): p. 7820-9.

55. Schubert A, Gentner E, Bohn K, Schwarz M, Mertens T, Sauerbrei A. Single nucleotide polymorphisms of thymidine kinase and DNA polymerase genes in clinical herpes simplex virus type 1 isolates associated with different resistance phenotypes. Antiviral Res. 2014;107: p. 16-22.

56. Stranska R, van Loon AM, Bredius RG, Polman M, Nienhuis E, Beersma MF, Lankester AC, Schuurman R. Sequential switching of DNA polymerase and thymidine kinase-mediated HSV-1 drug resistance in an immunocompromised child. Antivir Ther. 2004;9(1): p. 97-104.

57. Suzutani T, Ishioka K, De Clercq E, Ishibashi K, Kaneko H, Kira T, Hashimoto K, Ogasawara M, Ohtani K, Wakamiya N, Saijo M. Differential mutation patterns in thymidine kinase and DNA polymerase genes of herpes simplex virus type 1 clones passaged in the presence of acyclovir or penciclovir. Antimicrob Agents Chemother. 2003;47(5): p. 1707-13.

58. van der Beek MT, Claas EC, van der Blij-de Brouwer CS, Morfin F, Rusman LG, Kroes AC, Vossen AC. Rapid susceptibility testing for herpes simplex virus type 1 using real-time PCR. J Clin Virol. 2013;56(1): p. 19-24.

59. Huang L, Ishii KK, Zuccola H, Gehring AM, Hwang CB, Hogle J, Coen DM. The enzymological basis for resistance of herpesvirus DNA polymerase mutants to acyclovir: relationship to the structure of alpha-like DNA polymerases. Proc Natl Acad Sci U S A. 1999;96(2): p. 447-52.

60. Pavić I, Hartmann A, Zimmermann A, Michel D, Hampl W, Schleyer I, et al. Flow cytometric analysis of herpes simplex virus type 1 susceptibility to aciclovir, ganciclovir, and foscarnet. Antimicrob Agents Chemother. 1997;41(12):2686-92. 92.

61. Tardif KD, Jorgensen S, Langer J, Prichard M, Schlaberg R. Simultaneous titration and phenotypic antiviral drug susceptibility testing for herpes simplex virus 1 and 2. J Clin Virol. 2014;61(3):382-6.

62. Tebas P, Stabell EC, Olivo PD. Antiviral susceptibility testing with a cell line which expresses betagalactosidase after infection with herpes simplex virus. Antimicrob Agents Chemother. 1995;39(6):1287-91.

63. Stránská R, van Loon AM, Polman M, Schuurman R. Application of Real-Time PCR for Determination of Antiviral Drug Susceptibility of Herpes Simplex Virus. Antimicrob Agents Chemother. 2002;46(9):2943-7. 
64. Thi TN, Deback C, Malet I, Bonnafous P, Ait-Arkoub Z, Agut H. Rapid determination of antiviral drug susceptibility of herpes simplex virus types 1 and 2 by real-time PCR. Antiviral Res. 2006;69(3):152-7.

65. van der Beek MT, Claas ECJ, van der Blij-de Brouwer CS, Morfin F, Rusman LG, Kroes ACM, et al. Rapid susceptibility testing for herpes simplex virus type 1 using real-time PCR. J Clin Virol. 2013;56(1):19-24.

66. Piret J, Goyette N, Boivin G. Novel Method Based on Real-Time Cell Analysis for Drug Susceptibility Testing of Herpes Simplex Virus and Human Cytomegalovirus. J Clin Microbiol. 2016;54(8):2120-7.

67. Danve C, Morfin F, Thouvenot D, Aymard M. A screening dye-uptake assay to evaluate in vitro susceptibility of herpes simplex virus isolates to acyclovir. J Virol Methods. 2002;105(2):207-217.

68. Mercier-Darty M, Boutolleau D, Rodriguez C, Burrel S. Added value of ultra-deep sequencing (UDS) approach for detection of genotypic antiviral resistance of herpes simplex virus (HSV). Antiviral Res. 2019;168:128-133.

69. Karamitros T, Harrison I, Piorkowska R, Katzourakis A, Magiorkinis G, Mbisa JL. De Novo Assembly of Human Herpes Virus Type 1 (HHV-1) Genome, Mining of Non-Canonical Structures and Detection of Novel Drug-Resistance Mutations Using Short- and Long-Read Next Generation Sequencing Technologies. PLoS One. 2016;11(6):e0157600.

70. Funderburgh ML, Funderburgh JL, Chandler JW. Thymidine kinase activity of ocular herpes simplex isolates resistant to IUDR therapy. Invest Ophthalmol Vis Sci. 1986;27(10):1546-1548.

71. Oram RJ, Marcellino D, Strauss D, et al. Characterization of an acyclovir-resistant herpes simplex virus type 2 strain isolated from a premature neonate. J Infect Dis. 2000;181(4):1458-1461

72. Saijo M, Suzutani T, Niikura M, Morikawa S, Kurane I. Importance of C-terminus of herpes simplex virus type 1 thymidine kinase for maintaining thymidine kinase and acyclovir-phosphorylation activities. J Med Virol. 2002;66(3):388-393.

73. Pilger BD, Perozzo R, Alber F, Wurth C, Folkers G, Scapozza L. Substrate diversity of herpes simplex virus thymidine kinase. Impact of the kinematics of the enzyme. I Biol Chem. 1999;274(45):31967-31973.

74. Frobert E, Ooka T, Cortay JC, Lina B, Thouvenot D, Morfin F. Herpes simplex virus thymidine kinase mutations associated with resistance to acyclovir: a site-directed mutagenesis study. Antimicrob Agents Chemother. 2005;49(3):1055-1059.

75. Frobert E, Ooka T, Cortay JC, Lina B, Thouvenot D, Morfin F. Resistance of herpes simplex virus type 1 to acyclovir: thymidine kinase gene mutagenesis study. Antiviral Res. 2007;73(2):147-150. 
76. Bestman-Smith J, Schmit I, Papadopoulou B, Boivin G. Highly reliable heterologous system for evaluating resistance of clinical herpes simplex virus isolates to nucleoside analogues. $J$ Virol. 2001;75(7):3105-3110.

77. Shiota $T$, Lixin $W$, Takayama-Ito $M$, et al. Expression of herpes simplex virus type 1 recombinant thymidine kinase and its application to a rapid antiviral sensitivity assay. Antiviral Res. 2011;91(2):142-149.

78. Malartre N, Boulieu R, Falah N, et al. Effects of mutations on herpes simplex virus 1 thymidine kinase functionality: an in vitro assay based on detection of monophosphate forms of acyclovir and thymidine using HPLC/DAD. Antiviral Res. 2012;95(3):224-228.

79. van Velzen $M$, Missotten $T$, van Loenen FB, et al. Acyclovir-resistant herpes simplex virus type 1 in intra-ocular fluid samples of herpetic uveitis patients. J Clin Virol. 2013;57(3):215-221.

80. Sauerbrei A, Liermann K, Bohn K, et al. Significance of amino acid substitutions in the thymidine kinase gene of herpes simplex virus type 1 for resistance. Antiviral Res. 2012;96(2):105-107.

81. Sauerbrei A, Vödisch S, Bohn K, Schacke M, Gronowitz S. Screening of herpes simplex virus type 1 isolates for acyclovir resistance using DiviTum ${ }^{\circledR}$ assay. J Virol Methods. 2013;188(1-2):70-72.

82. Burrel S, Bonnafous $\mathrm{P}$, Hubacek $\mathrm{P}$, Agut $\mathrm{H}$, Boutolleau D. Impact of novel mutations of herpes simplex virus 1 and 2 thymidine kinases on acyclovir phosphorylation activity. Antiviral Res. 2012;96(3):386-390.

83. Larder BA, Darby G. Susceptibility to other antiherpes drugs of pathogenic variants of herpes simplex virus selected for resistance to acyclovir. Antimicrob Agents Chemother. 1986;29(5):894-898. 84. Sacks SL, Wanklin RJ, Reece DE, Hicks KA, Tyler KL, Coen DM. Progressive esophagitis from acyclovir-resistant herpes simplex. Clinical roles for DNA polymerase mutants and viral heterogeneity?. Ann Intern Med. 1989;111(11):893-899.

85. Marcy Al, Hwang CB, Ruffner KL, Coen DM. Engineered herpes simplex virus DNA polymerase point mutants: the most highly conserved region shared among alpha-like DNA polymerases is involved in substrate recognition. J Virol. 1990;64(12):5883-5890.

86. Hwang YT, Liu BY, Coen DM, Hwang CB. Effects of mutations in the Exo III motif of the herpes simplex virus DNA polymerase gene on enzyme activities, viral replication, and replication fidelity. $J$ Virol. 1997;71(10):7791-7798.

87. Cunningham C, Davison AJ. A cosmid-based system for constructing mutants of herpes simplex virus type 1. Virology. 1993;197(1):116-124.

88. Bestman-Smith J, Boivin G. Drug resistance patterns of recombinant herpes simplex virus DNA polymerase mutants generated with a set of overlapping cosmids and plasmids. I Virol. 2003;77(14):7820-7829. 
89. Sergerie $\mathrm{Y}$, Boivin $\mathrm{G}$. Thymidine kinase mutations conferring acyclovir resistance in herpes simplex type 1 recombinant viruses. Antimicrob Agents Chemother. 2006;50(11):3889-3892.

90. Robinet-Perrin A, Tumiotto C, Cornut $T$, et al. Input of recombinant phenotyping for the characterization of a novel acyclovir-resistance mutation identified in a patient with recurrent herpetic keratitis. Antiviral Res. 2019;168:183-186.

91. Brunnemann AK, Liermann K, Deinhardt-Emmer S, et al. Recombinant herpes simplex virus type 1 strains with targeted mutations relevant for aciclovir susceptibility. Sci Rep. 2016;6:29903.

92. Brunnemann AK, Hoffmann A, Deinhardt-Emmer S, et al. Relevance of non-synonymous thymidine kinase mutations for antiviral resistance of recombinant herpes simplex virus type 2 strains. Antiviral Res. 2018;152:53-57.

93. Borst EM, Benkartek C, Messerle M. Use of bacterial artificial chromosomes in generating targeted mutations in human and mouse cytomegaloviruses. Curr Protoc Immunol. 2007; Chapter 10: Unit 1032.

94. Chou S, Marousek GI, Van Wechel LC, Li S, Weinberg A. Growth and drug resistance phenotypes resulting from cytomegalovirus DNA polymerase region III mutations observed in clinical specimens. Antimicrob Agents Chemother. 2007;51(11):4160-4162.

95. Martin M, Goyette N, Ives J, Boivin G. Incidence and characterization of cytomegalovirus resistance mutations among pediatric solid organ transplant patients who received valganciclovir prophylaxis. J Clin Virol. 2010;47(4):321-324.

96. Hantz S, Cotin S, Borst E, et al. Novel DNA polymerase mutations conferring cytomegalovirus resistance: input of BAC-recombinant phenotyping and 3D model. Antiviral Res. 2013;98(1):130-134. 97. Weller SK, Kuchta RD. The DNA helicase-primase complex as a target for herpes viral infection. Expert Opin Ther Targets. 2013;17(10):1119-1132.

98. Tyring S, Wald A, Zadeikis N, Dhadda S, Takenouchi K, Rorig R. ASP2151 for the treatment of genital herpes: a randomized, double-blind, placebo- and valaciclovir-controlled, dose-finding study. J Infect Dis. 2012;205(7):1100-10. 52.

99. Wald A, Timmler B, Magaret A, et al. Effect of Pritelivir Compared With Valacyclovir on Genital HSV-2 Shedding in Patients With Frequent Recurrences: A Randomized Clinical Trial [published correction appears in JAMA. 2017 Feb 14;317(6):648]. JAMA. 2016;316(23):2495-2503.

100. Biswas S, Smith C, Field HJ. Detection of HSV-1 variants highly resistant to the helicase-primase inhibitor BAY 57-1293 at high frequency in 2 of 10 recent clinical isolates of HSV-1. J Antimicrob Chemother. 2007;60(2):274-9.

101. Chono K, Katsumata K, Kontani T, Kobayashi M, Sudo K, Yokota T, et al. ASP2151, a novel helicase-primase inhibitor, possesses antiviral activity against varicella-zoster virus and herpes simplex virus types 1 and 2. J Antimicrob Chemother. 2010;65(8):1733-41. 
102. Quenelle DC, Birkmann A, Goldner T, Pfaff T, Zimmermann H, Bonsmann S, et al. Efficacy of pritelivir and aciclovir in the treatment of herpes simplex virus infections in a mouse model of herpes simplex encephalitis. Antiviral Res. 2018;149:1-6.

103. Ohtsu Y, Susaki Y, Noguchi K. Absorption, Distribution, Metabolism, and Excretion of the Novel Helicase-Primase Inhibitor, Amenamevir (ASP2151), in Rodents. Eur J Drug Metab Pharmacokinet. 2018;43(6):693-706.

104. Kleymann G, Fischer R, Betz UAK, Hendrix M, Bender W, Schneider U, et al. New helicaseprimase inhibitors as drug candidates for the treatment of herpes simplex disease. Nat Med. 2002;8(4):392-8.

105. James SH, Prichard MN. Current and future therapies for herpes simplex virus infections: mechanism of action and drug resistance. Curr Opin Virol. 2014;8:54-61.

106. Chono K, Katsumata K, Kontani T, Shiraki K, Suzuki H. Characterization of virus strains resistant to the herpes virus helicase-primase inhibitor ASP2151 (Amenamevir). Biochem Pharmacol. 2012;84(4):459-467.

107. Field HJ, Biswas S. Antiviral drug resistance and helicase-primase inhibitors of herpes simplex virus. Drug Resist Updat. 2011;14(1):45-51. 